\title{
Microstructure of the Mg-4Y-3RE-Zr (WE43) Magnesium Alloy Produced by 3D Printing
}

\author{
Patrícia Krištofová1, Jiří Kubásek ${ }^{1}$, Dalibor Vojtěch ${ }^{1}$, David Paloušek ${ }^{2}$, Jan Suchý ${ }^{2}$ \\ ${ }^{1}$ Faculty of chemical technology, Department of Metals and Corrosion Engineering, University of Chemistry and \\ Technology Prague, Technická 5, 16628 Praha 6 - Dejvice, Czech Republic. E-mail: Patricia.Kristofova@vscht.cz, \\ Jiri.Kubasek@vscht.cz, Dalibor.Vojtech@vscht.cz \\ ${ }^{2}$ Faculty of Mechanical Engineerinng, Department of Reverse Engineering and Additive Technologies, Brno University \\ of Technology, Antonínská 548/1, 60190 Brno, Czech Republic. E-mail: palousek@fme.vutbr.cz, Jan.Suchy1@vut.cz
}

\begin{abstract}
In this study, the three microstructure of the as-cast, hot-extruded, and 3D printed Mg-4Y-3RE-Zr (WE43) magnesium alloy was studied. The selective laser melting (SLM) process was used for 3D printing. The study was aimed at mapping the microstructure of a 3D printed magnesium alloy produced by the SLM process. Magnesium alloys made in the form of 3D printing are relatively new production processes. The study therefore this process compared with current processes, which are now well known and mapped. It was therefore studied the microstructure produced by three different processes of production. The microstructure and chemical composition of present phases were studied using scanning electron microscopy (SEM) and energy dispersive $x-$ ray spectrometry (EDS). Based on the microstructural examination, significant differences were found between the materials produced by different production processes. The microstructure of the as-cast alloy consisted of relatively coarse $\alpha$-Mg dendrites surrounded by eutectics containing intermetallic phases rich-in alloying elements. During hot extrusion, the eutectics fragmented into fine particles which arranged into rows parallel to the extrusion direction. The 3D printed alloy was characterized by significantly refined microstructure due to a high cooling rate during the SLM process. It consisted of very fine dendrites of $\alpha$-Mg and interdendritic network enriched-in the alloying elements. In addition, there were also oxides covering original powder particles and the material showed also some porosity that is a common feature of 3D printed alloys.
\end{abstract}

Keywords: Magnesium, Mg-4Y-3RE-Zr alloy, WE43 alloy, 3D printing, selective laser melting

\section{Introduction}

Magnesium belongs among the widespread elements of the Earth's crust. Magnesium alloys are characterized by a low density of about $1700 \mathrm{~kg} / \mathrm{m}^{3}$ and a high strengthto-weight ratio which make them interesting materials for a variety of technical applications [1,2]. Because of the hexagonal crystallographic structure, the coldformability of $\mathrm{Mg}$ alloys is low at room temperature, but it significantly increases at higher temperatures (200$300^{\circ} \mathrm{C}$ ) due to activation of other slip systems in the crystal lattice. Strength of $\mathrm{Mg}$ alloys depends on chemical composition and production route, and can be as high as $400 \mathrm{MPa}$. The mostly used Mg alloys contain $\mathrm{Al}$ and $\mathrm{Zn}$ as essential alloying elements. The main drawback of the $\mathrm{Mg}-\mathrm{Al}-\mathrm{Zn}$ alloys (AZ types) is a low mechanical stability at elevated temperatures above $150^{\circ} \mathrm{C}$. To overcome this drawback, Mg-RE alloys have been developed which are able to withstand temperatures up to $250^{\circ} \mathrm{C}$ and more [3]. In these alloys, stable $\mathrm{Mg}-\mathrm{RE}$ precipitates are formed that hinder dislocation motion at higher temperatures. The well known representative of this group of alloys is the WE43 (Mg-4Y-3RE-0.5Zr) alloy showing a good thermal stability, high strength and good corrosion resistence. The final high strength of this alloy is generally achieved by heat treatment consisting of solution annealing at $525^{\circ} \mathrm{C} / 8$ hours, water quenching and artificial aging at $250^{\circ} \mathrm{C} / 16$ hours. Magnesium alloys are increasingly used in the automotive or aviation industry due to their desired combination of good mechanical strength and low density. However, their low weight can be further reduced significantly if porous structures are formed $[4,5]$.

The term additive manufacturing (AM) involves various promising and advanced material technologies which enable almost shape freedom of produced parts with unlimited internal architecture and structure. Of course, highly porous materials can also be produced by AM processes. One of the most widespread AM methods is selective laser melting (SLM), where the laser beam selectively melts powder materials layer by layer to progressively build up a desired component. The melting of each layer proceeds selectively in locations defined by the 3D computer model of a component. The SLM process can efficiently produce very complex geometric shapes that would, otherwise, require very expensive and time-consuming manufacturing processes [5-7].

Nowadays, 3D printing of magnesium alloys by the SLM process is a relatively difficult task and various processing barriers and problems must be solved. One of them is connected with a high reactivity, or even flammability, of magnesium powder and, thus, a high tendency to form harmful oxide particles inside a 3D printed parts. For this reasons, publications providing information on $3 \mathrm{D}$ printing of magnesium alloys are scarce $[7,8]$. In the present work, rectangular samples of WE43 magnesium alloy were successfully 3D printed at Brno University of Technology by the SLM process. The microstructure of the samples was studied in detail by SEM and EDS, and compared to those of the identical material prepared by simple gravity casting and hot extrusion. 


\section{Materials and methods}

\subsection{Specimens preparation}

In this work we studied samples of WE43 magnesium alloy prepared by three different manufacturing processes. The first sample was an as-cast ingot of $60 \times 80 \times 500 \mathrm{~mm}$ in size purchased from an industrial supplier. The second WE43 alloy sample was prepared by hot extrusion of the ingot. Cylinders with a diameter of $30 \mathrm{~mm}$ and a length of $60 \mathrm{~mm}$ were directly cut from the ingot and then extruded at $400^{\circ} \mathrm{C}$, extrusion rate of 2 $\mathrm{mm} / \mathrm{s}$ and extrusion ratio of 16 . The resulting extruded rods had a diameter of $7.5 \mathrm{~mm}$.

The most important material studied in this work was prepared by the SLM 3D printing process on the SLM Solution 280 HL machine (SLM Solutions AG, Lübeck,
Germany) equipped with 400W YLR-Laser (IPG Photonics, Oxford, MA, USA) working with continuous wave mode. The laser has Gaussian profile with spot size diameter of $82 \mu \mathrm{m}$ focused at the processing plane. The input material was a WE43 alloy powder purchased from an industrial supplier. The powder was produced by inert gas atomization of melt and consisted of almost spherical particles with size between 30-60 $\mu \mathrm{m}$. During the SLM process, the building chamber was filled with purified argon to prevent excessive oxidation or burning of the powder during its heating and melting by laser beam. Overpressure in building chamber was (12-20) mbar and oxygen level was $(0.1-0.3) \%$. Rectangular samples with dimensions of $15 \times 5 \times 60 \mathrm{~mm}$ were produced by this technology. All parameters sample production by the SLM process are shown in Tab. 1.

Tab. 1 SLM parameters.

\begin{tabular}{|ll|ll|}
\hline SLM parameters & & \\
\hline Machine & $\begin{array}{l}\text { SLM 280HL (SLM solutions } \\
\text { AG) }\end{array}$ & Atmosphere & Argon \\
\hline Max. laser power & $400 \mathrm{~W}$ & Overpressure & $12-20 \mathrm{mbar}$ \\
\hline Laser & Ytterbium fibre laser beam & Oxygen level & $0.1-0.3 \%$ \\
\hline $\begin{array}{l}\text { Operational Beam Fo- } \\
\text { cus }\end{array}$ & $82 \mu \mathrm{m}$ & $\begin{array}{l}\text { Reduction built plate } \\
\text { temp. }\end{array}$ & $80^{\circ} \mathrm{C}$ \\
\hline Beam & Gaussian beam & Built plate temp. & $120^{\circ} \mathrm{C}$ \\
\hline Layer thickness & $50 \mu \mathrm{m}$ & & \\
\hline
\end{tabular}

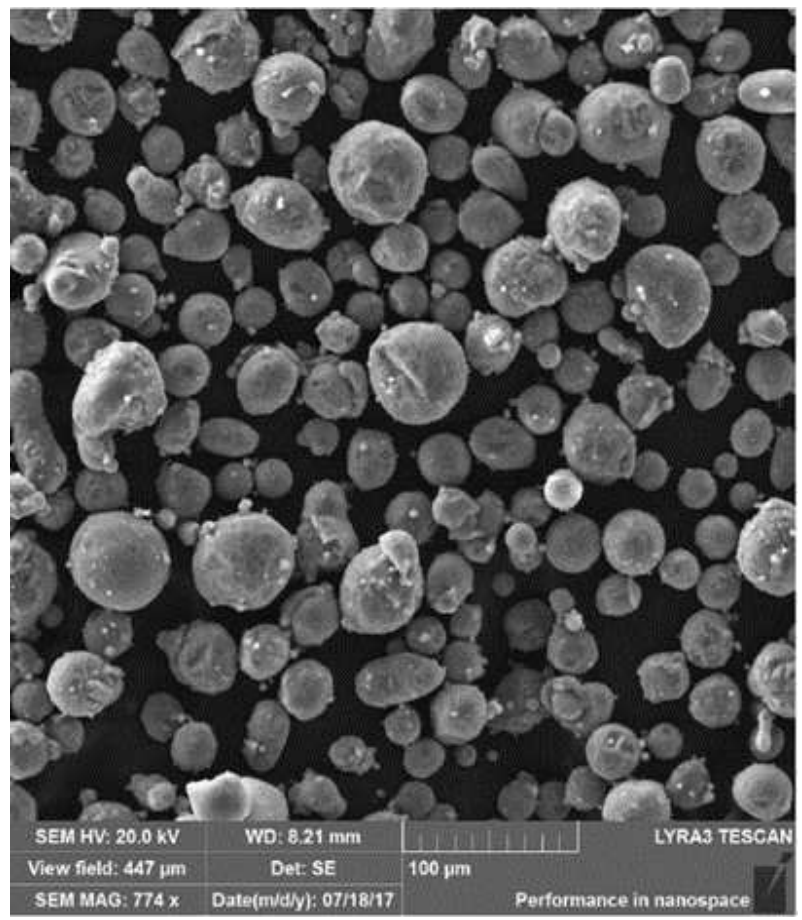

Fig. 1 SEM micrographs of the WE43 alloy powder

The analysis revealed that $10 \%$ of the WE43 alloy powder particles had a size of $26.9 \mu \mathrm{m}, 50 \%$ to $39.8 \mu \mathrm{m}$ and $90 \%$ to $57.9 \mu \mathrm{m}$. Thus, the powder contains a sufficient amount of both larger and smaller particles. With respect to the particle size, the size of the building layer was $50 \mu \mathrm{m}$. The shape of the particles is also shown in Fig.1

\subsection{Microstructure characterization}

For microscopic observations, the standard metallographic procedure was applied including grinding on $\mathrm{SiC}$ papers with progressively decreasing $\mathrm{SiC}$ grain size. The final grinding was performed on the P2500 SiC paper. Subsequently, the samples were polished on diamond paste with a grain size of $0.2 \mu \mathrm{m}$ followed by final polishing on Etosil E (Silicon dioxide, chemically prepared) to obtain mirror polish of the sample. In order to visualize the microstructure for SEM observation chemical etching by $2 \%$ Nital was applied. The microstructure examination and chemical microanalysis of the samples was carried out using TescanVega3 LMU scanning electron microscope (SEM, acceleration voltage of $20 \mathrm{kV}$ ) equipped with energy dispersive spectrometer (EDS, Oxford Instruments Inca 350).

\section{Results and Discussion}

Overall views of the microstructures of as-cast, hot extruded and 3D printed WE43 alloy samples are shown in Fig. 2. 

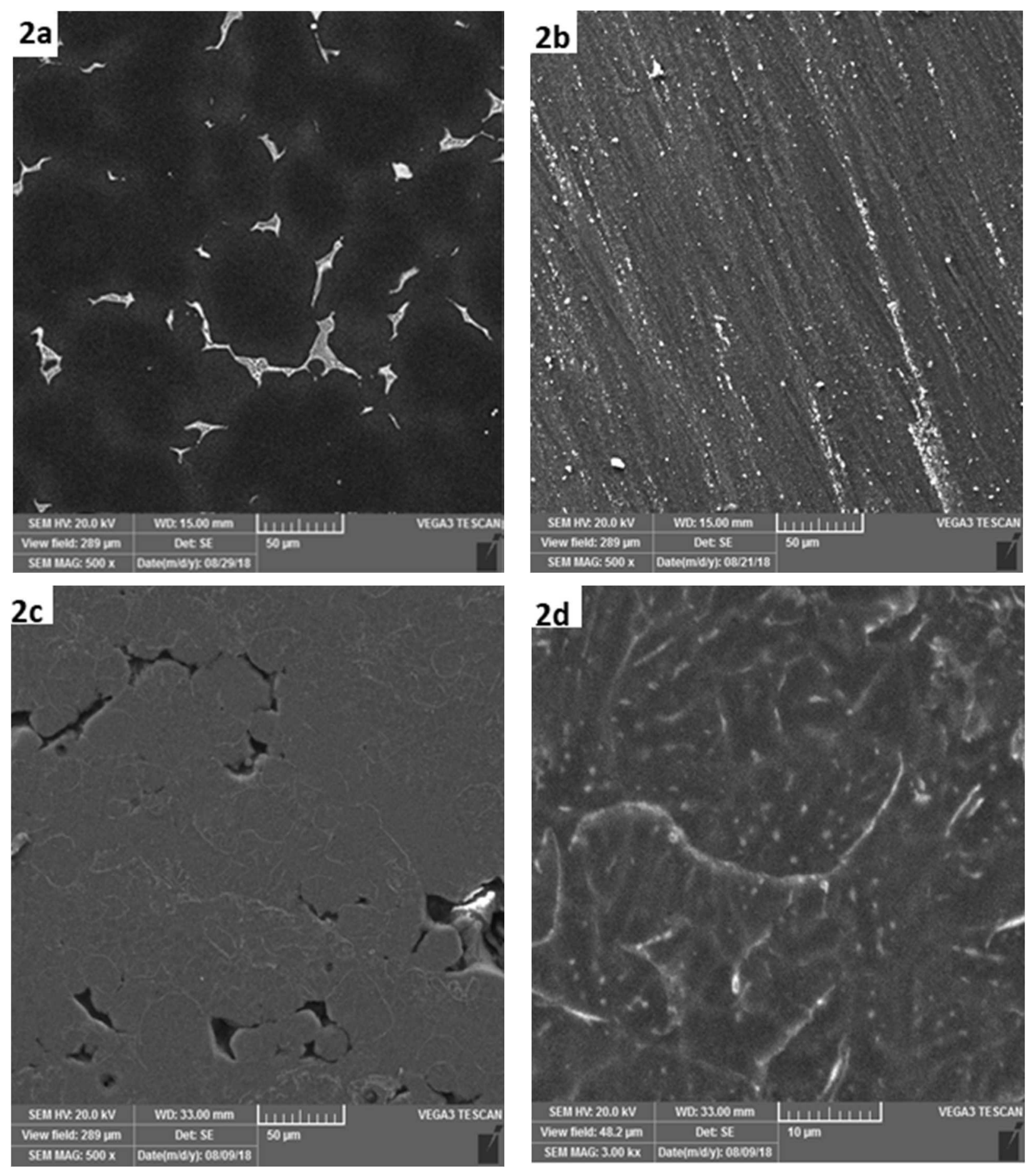

Fig. 2 SEM micrographs of the WE43 alloy: a) as-cast, b) hot extruded, c) 3D printed by SLM, d) 3D printed by SLMdetail.

It can be seen in Fig. 2 that the as-cast alloy (Fig. 2a) is characterized by a relatively coarse microstructure consisting of $\alpha-\mathrm{Mg}$ dendrites (dark) and a discontinuous interdendritic eutectic network (light). Due to relatively large dimensions of the as-cast ingot and, thus, low cooling rates, the average thiskness of dendritic branches achieves almost $50 \mu \mathrm{m}$. In addition, microsegregation, i.e. enrichment of dendrite boundaries in alloying elements, can be observed. According to literature [6, 9-11], interdendritic eutectics contains mainly $\alpha-\mathrm{Mg}+\beta$ -
$\mathrm{Mg}_{14} \mathrm{Nd}_{2} \mathrm{Y}$ phases.

Fig. 2b illustrates the hot extruded sample. It is apparent that hot extrusion modifies the microstructure considerably. The initial eutectic network was broken by extrusion and intermetallic $\beta-\mathrm{Mg}_{14} \mathrm{Nd}_{2} \mathrm{Y}$ phase fragmented into very fine particles of a few micrometers in size (light particles in Fig. 2b). Besides, $\beta-\mathrm{Mg}_{14} \mathrm{Nd}_{2} \mathrm{Y}$ particles became arranged into rows parallel to the extrusion direction $[12,13]$. 


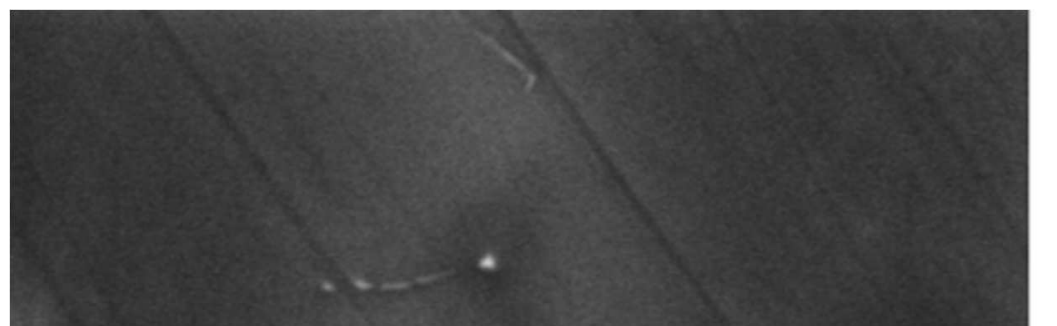

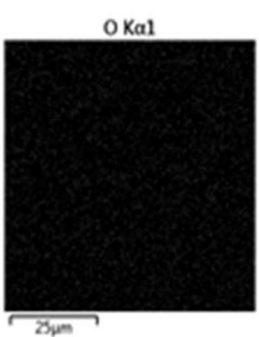

Mg Kal 2

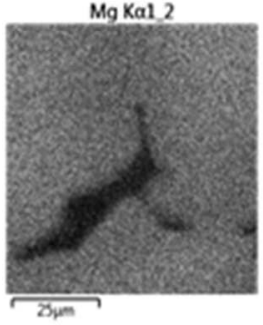

$Y\lfloor a \mid$

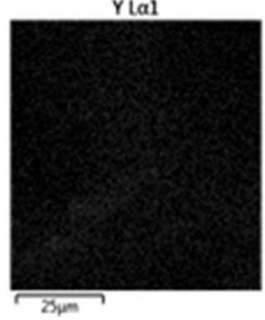

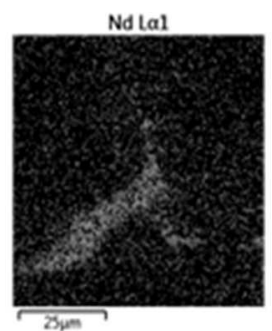

Gd $|\alpha|$

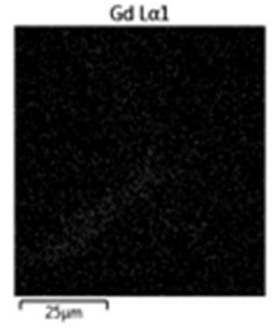

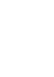

Tab. 2 Chemical composition (in wt. \%) at points in Fig. 3 (EDS).

\begin{tabular}{|l|c|c|c|c|}
\hline Element & $\mathrm{O}$ & $\mathrm{Mg}$ & $\mathrm{Y}$ & $\mathrm{Nd}$ \\
\hline Point 1 & 0.92 & 70.05 & 10.39 & 18.63 \\
\hline \hline Point 2 & 1.32 & 92.51 & 4.32 & 1.85 \\
\hline
\end{tabular}

Fig. 2c shows the microstructure of the 3D printed sample at the same magnification as previous ones. The microstructure totally differs from those of as-cast and extruded material. It is composed of regions (grey) of approx. 20-50 $\mu \mathrm{m}$ in size, some of them having almost spherical shape, surrounded by thin boundaries (light). In addition, residual porosity is observed as dark areas between grey regions. The shape and size of grey regions indicates that these regions correspond to original powder particles, either totally or partly melted by laser beam. A more detailed image in

Fig. 2d shows very fine internal microstructure of these particles. It contains $\alpha-\mathrm{Mg}$ dendrites (dark) surrounded by interdendritic regions (light) enriched in $\mathrm{Y}$ and RE elements. The average thiskness of dendritic branches is only approx. $3 \mu \mathrm{m}$, suggesting very high cooling rates during the SLM process. In literature focused on the SLM process, cooling rates of $10^{3}-10^{6} \mathrm{~K} / \mathrm{s}$ are often reported [13].

In order to obtain information on elements distribution in the structure of materials, EDS point analysis and distribution maps of elements were measured, see Fig. 3-5. In Fig. 3, there is a detailed view of the as-cast microstructure together with elements distribution map. It confirms that the bright eutectics is strongly enriched in Y and RE metals (Nd and Gd). Tab. $\mathbf{2}$ demonstrates that the concentration of $\mathrm{Nd}$ and $\mathrm{Y}$ in the eutectics achieves 19 and 10 wt. \%, respectively (point 1 in Fig. 3). On the other hand, in the centre of $\alpha-\mathrm{Mg}$ dendrites (point 2 in Fig. 3) the concentrations are significantly lower. Another important finding is that the oxygen concentration is very low in the as-cast material. Similar situation is observed in the case of the hotextruded material (Fig. 4, Tab. 3). Both the element distribution map and point analysis indicate enrichment of light intermetallic phases in $\mathrm{Y}$ and $\mathrm{Nd}$. In contrast to the as-cast alloy, the difference between concentrations of these elements in intermetallic phases and $\alpha-\mathrm{Mg}$ phase is small due to the spatial accuracy of EDS analysis [9, 12, 13]. As in the previous case, the amount of $\mathrm{O}$ is low in the hot extruded alloy. 

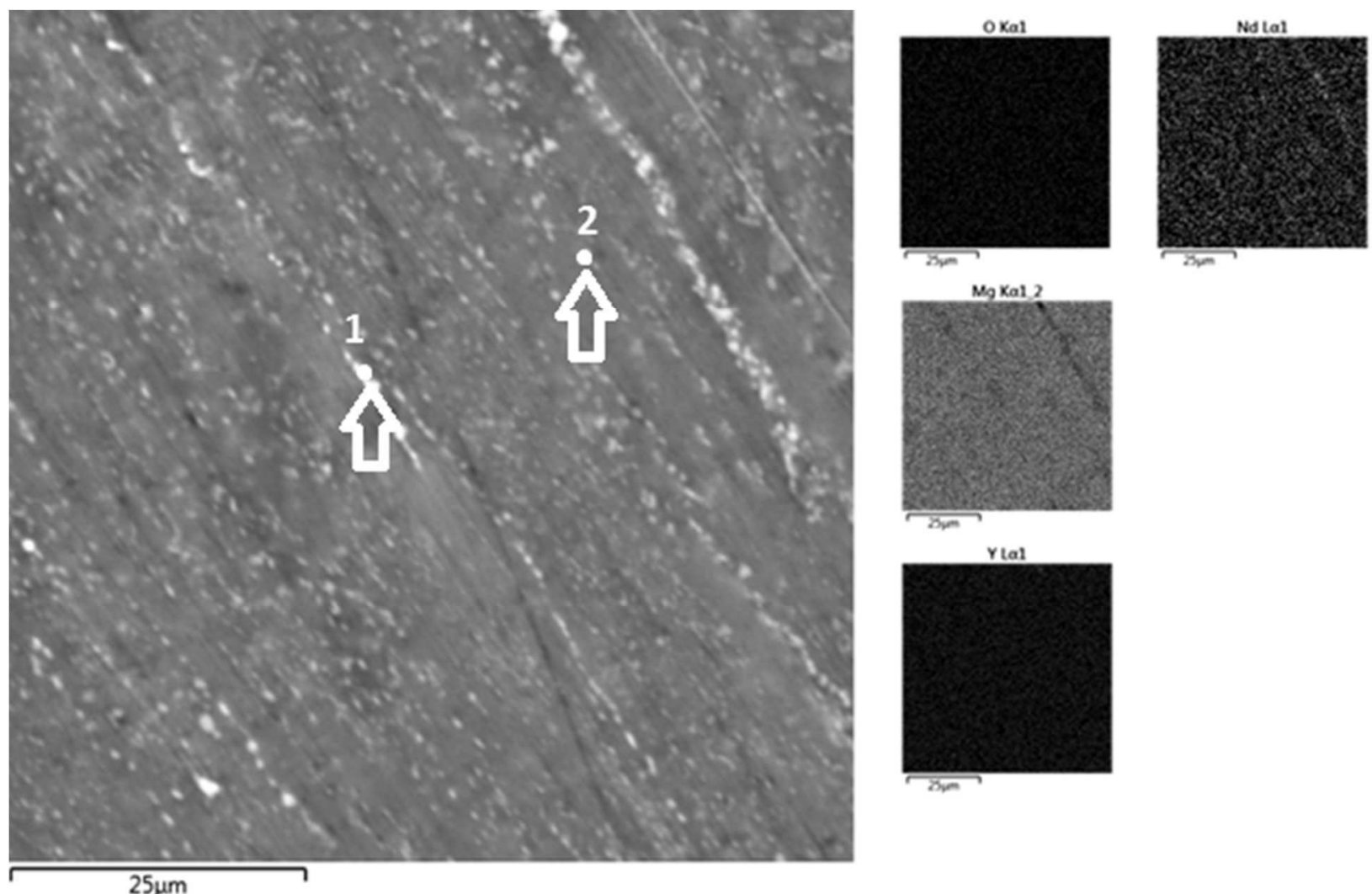

Mg Kal 2

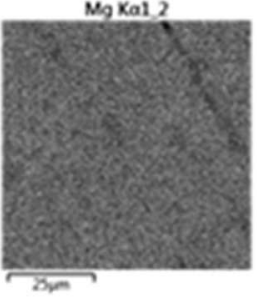

Yta

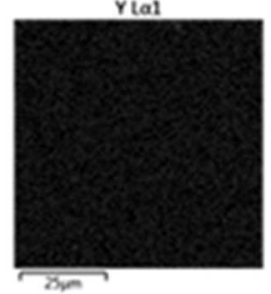

Fig. 4 Microstructure of the hot extruded WE43 alloy (SEM) and elements distribution maps (EDS).

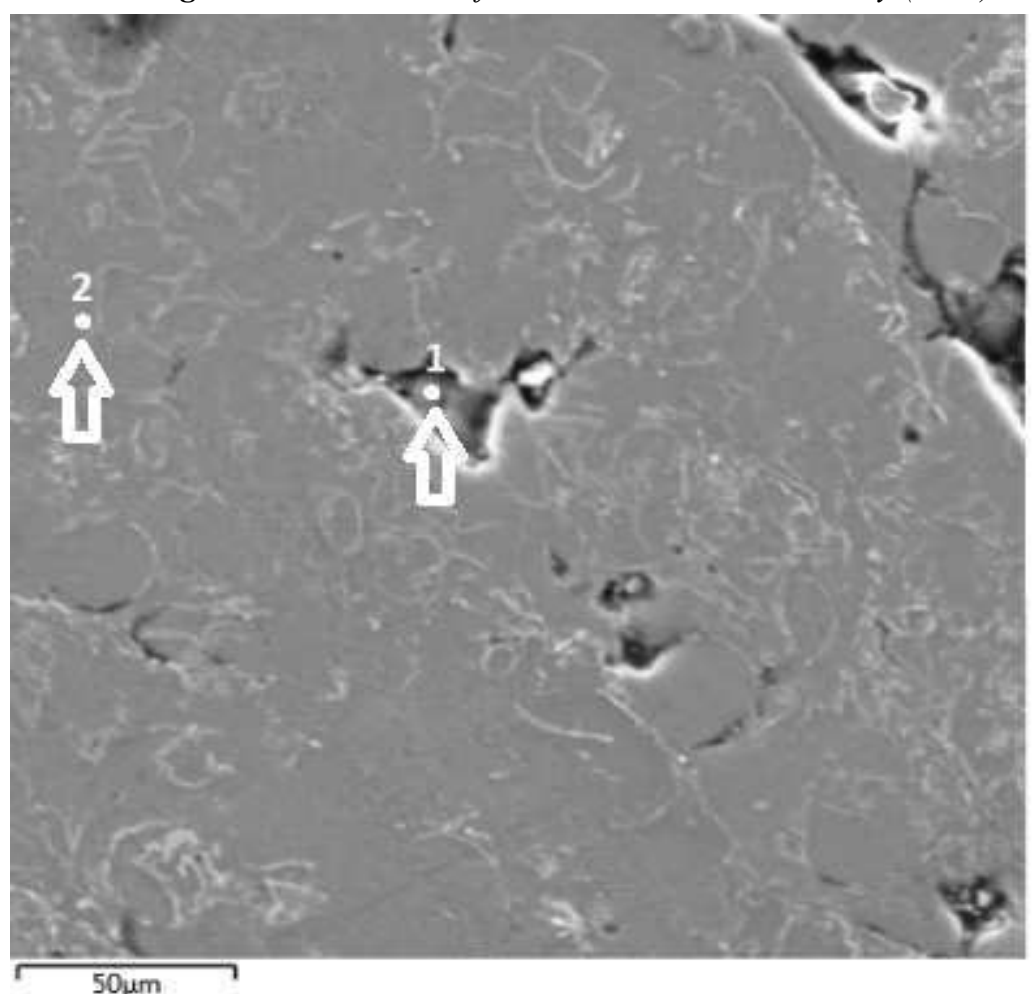

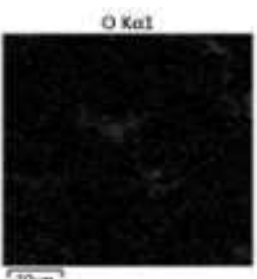

Ma Kat 2

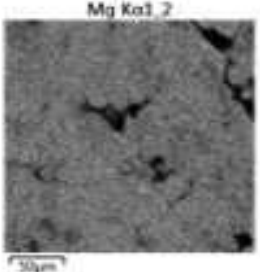

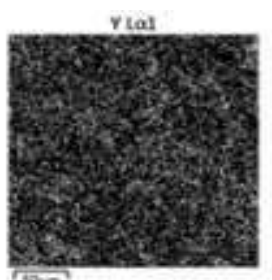

s़्राल

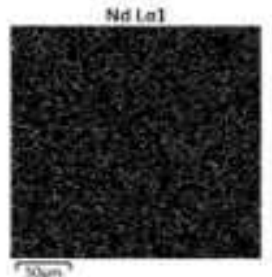

Fig. 5 Microstructure of the SLM WE43 alloy (SEM) and elements distribution maps (EDS).

Tab. 3 Chemical composition (in wt. \%) at points in Fig. 4 (EDS).

\begin{tabular}{|l|c|c|c|c|}
\hline Element & $\mathrm{O}$ & $\mathrm{Mg}$ & $\mathrm{Y}$ & $\mathrm{Nd}$ \\
\hline Point 1 & 0.53 & 89.50 & 4.36 & 5.61 \\
\hline \hline Point 2 & 0.48 & 93.42 & 3.93 & 2.16 \\
\hline
\end{tabular}

Tab. 4 Chemical composition (in wt. \%) at points in Fig. $5(E D S)$.

\begin{tabular}{|l|c|c|c|c|}
\hline Element & $\mathrm{O}$ & $\mathrm{Mg}$ & $\mathrm{Y}$ & $\mathrm{Nd}$ \\
\hline Point 1 & 11.62 & 65.56 & 2.86 & 3.51 \\
\hline Point 2 & 0.25 & 94.96 & 2.31 & 2.48 \\
\hline
\end{tabular}


Fig. 5 and Tab. 4 characterize the element dostribution in the WE43 alloy prepared by the SLM 3D printing technology. Here, the situation differs from the as-cast and hot extruded alloy. First, element maps and point analysis demonstrate an increased concentration of oxygen in the material which is located mainly in pores (point 1) and also at bondaries between melted powder particles. In the particle interior the O-concentration is very low (point 2). Second, element map in Fig. 5 also indicates increased content of $\mathrm{Y}$ at powder particle boundaries. It can be assumed, that partial oxidation of the powder occurred during the SLM process inside the building chamber. Most probably, the atmosphere contained traces of residual oxygen which reacted preferentially with yttrium due to a high chemical affinity of these elements. For this reason, imperfect connection between powder particles and porosity are observed. The aim of our further study will be to eliminate the harmful influence of residual oxygen and to produce pore-free compact material $[5,9]$.

\section{Conclusion}

The main objective of this article was to describe the differences between microstructures of the WE43 magnesium alloy prepared in three different ways: casting, extrusion and 3D printing (SLM). Processes of production casting and extrusion are well known and nowadays already used. Many studies deal with the description of their microstructure. However, 3D printing of alloys and especially magnesium alloys represents a relatively new process. The work was therefore more focused on describing the microstructure produced by 3D printing and comparison with other processes. The most important results show that, the microstructure of the SLM material is extremely fine due to a high cooling rates in the process. The SLM material contains a high concentration of oxygen due to a high affinity of the alloy to this gas. Due to oxygen, imperfect connection between powder particles and porosity create.

\section{Acknowledgement}

Authors wish to thank specific university research (MSMT No 20-SVV/2018) for the financial support of this research.

\section{References}

[1] MISRA, K.C. (2012). Introduction to Geochemistry: Principles and Applications, ed. 1. 2012. p. 452.

[2] KUBÁSEK, J. (2016). Properties of magnesium alloys usable as biodegradable materials, in Department of Metals and Corrosion Engineering.
Disertaton, 2016, University of Chemistry and Technology, Prague.

[3] HRIVŇÁK, I.; HRIVŇÁKOVÁ., D. (2011). Materialography, ed. 1. 2011, Bratislava: STU.

[4] KUBÁSEK, J.; VOJTĚCH, D. (2014). Mg alloys for high temperature applications. Slévarenství, 2014. LXII, No. 11-12: p. 408.

[5] FOUSOVÁ, M. (2016). Properties of metallic materials produced by $3 \mathrm{D}$ printing technology, in Department of Metals and Corrosion Engineering. Master Thesis, 2016, University of chemistry and technology, Prague.

[6] FOUSOVÁ, M.VOJTĚCH, D.; FOJT, J. (2016). Microscopic Evaluation of 3D-Printed Materials Surface and Characteristic Microstructure. Manufacturing Technology, 2016. 16.

[7] ZHENG, B., ZHOU, Y.; SMUGERESKY, J. E., et. al. (2011). Thermal Behavior and Microstructure Evolution during Laser Deposition with Laser-Engineered Net Shaping, Part II, Experimental Investigation Discussion, . Metallurgical and Materials Transaction A, 2011. 42, No. 10: p. 3190-3199.

[8] RYAN. G.; PANDIT, A.A., D. P. (2006). Fabrication methods of porous metals for us in orthopedic applications. Biomaterials, 2006. 27, No. 13: p. 2651-2670.

[9] KUBÁSEK, J.; DVORSKÝ, D.; ČAVOJSKÝ, M.; VOJTĚCH, D.; BERONSKÁ, N.; FOUSOVÁ M. (2017). Superior Properties of Mg-4Y-3RE-Zr Alloy Prepared by Powder Metallurgy. Journal of Materials Sciences and Technology, 2017. 33(7): p. 652-660.

[10] OCHSNER, A.; ALTENBACH, H. (2017). Properties and Characterization of Modern Materials. 2017: Springer.

[11] JIANG, H.S., et al. (2017). Microstructure and mechanical properties of WE43 magnesium alloy fabricated by direct-chill casting. Materials Science and Engineering: A, 2017. 684: p. 158164.

[12] DVORSKÝ, D.; KUBÁSEK, J.; VOJTĚCH, D.; PRŮŠA, F.; NOVÁ, K. (2016). Preparation of WE43 Using Powder Metallurgy Route. Manufacturing Technology, 2016. 16, No. 4: p. 680-687.

DVORSKÝ, D.; KUBÁSEK, J.; VOJTĚCH, D.; ČAVOJSKÝ, M. (2016). Structure and mechanical properties of WE43 prepared by powder metallurgy route. Manufacturing Technology, 2016. 16, No. 5: p. 896-902. 